\title{
Espécies novas de Thygater Holmberg (Hymenoptera, Apoidea, Anthophoridae) ${ }^{1}$
}

Danúncia Urban ${ }^{2}$

\begin{abstract}
New species of Thygater Holmberg (Hymenoptera, Apoidea, Anthophoridae). Five new species of Eucerine bees from the genus Thygater Holmberg, 1884 are described: Thygater (Thygater) anae sp.n., Thygater (Thygater) armandoi sp.n. and Thygater (Thygater) minarum sp.n. from Brazil; Thygater (Thygater) ubirajarai sp.n. and Thygater (Thygater) laevis sp.n. from Venezuela.

KEY WORDS. Thygater, Eucerinae, Anthophoridae, Hymenoptera, taxonomy
\end{abstract}

Na revisão do gênero Thygater feita por URBAN (1967) as espécies foram agrupadas em dois sub-gêneros, fundamentados no número de artículos dos palpos maxilares, Thygater s. str. com três artículos, incluindo 15 espécies e Nectarodiaeta Holmberg, 1903, com quatro artículos e 10 espécies. Neste trabalho são descritas cinco espécies novas, todas baseadas em fêmeas, de Thygater s. str., T. ubirajarai sp.n. com metasoma arruivado como em T. rubricata (Smith, 1879) (Fig. 1); T. anae sp.n. e T. laevis sp.n. do grupo de espécies com os tergos amarelo-acastanhados; $T$. armandoi sp.n. com clípeo brilhante e liso medianamente como em T. palliventris (Friese, 1908), porém com o metasoma enegrecido e T. minarum sp.n. com os tergos distais amarelo-acastanhados; e o macho de T. anae sp.n.

O material tipo está depositado na Coleção de Entomologia Pe. J.S. Moure, Departamento de Zoologia, Universidade Federal do Paraná (DZUP). As medidas relacionadas nas descrições são dadas em milímetros. Nos comentários sobre as espécies são feitas referências aos ítens da chave publicada por URBAN (1967).

\section{Thygater (Thygater) ubirajarai sp.n.}

Fig. 2

Diagnose. Fêmea com pilosidade enegrecida na cabeça, mesosoma e pernas; tegumento ruivo-acastanhado nos tergos.

Holótipo fêmea. Tegumento preto na cabeça e mesosoma; mandíbulas castanho-avermelhadas; área malar castanha com mescla de amarelado; antenas castanhas na face ventral do segundo flagelômero ao apical; tégulas pretas; asas tingidas de castanho e veias pretas; pernas castanhas, com uma tonalidade mais clara nos tarsômeros; tergos ruivo-acastanhados, o segundo com nódoa enegrecida grande na base e margem castanha; esternos com grandes áreas de castanho-claro e enegrecido.

1) Contribuição número 1036 do Departamento de Zoologia, Universidade Federal do Paraná.

2) Departamento de Zoologia, Universidade Federal do Paraná. Caixa Postal 19020, 81531-990 Curitiba, Paraná, Brasil. Bolsista do CNPq. 
Pilosidade castanho-escura na cabeça e mesosoma; branca nos flancos do clípeo, paroculares inferiores, genas e occipício, mesclada com preta nas genas; pequenas áreas brancas nos cantos posteriores do mesoscuto; enegrecida nas pernas inclusive nos basitarsos, castanho-amarelada nos demais tarsômeros e face ventral dos basitarsos; fusca no tergo basal, amarelo-mélea e curta nos demais tergos, mais longa nos distais; amarelo-dourada nos esternos, muito curta no disco e longa na borda formando franja, com tufos laterais do terceiro ao quinto esterno.

Clípeo brilhante no meio, junto à sutura epistomal, fracamente elevado no disco porém sem formar carena; metade posterior do disco do mesoscuto brilhante e sem micro-reticulação, os pontos esparsos; tergos brilhantes, pontuação fina e esparsa nos três basais, pouco mais densa no quarto tergo, larga margem lisa no primeiro, mais estreita no segundo e muito estreita nos dois tergos seguintes.

Comprimento aproximado 14,87; comprimento da asa anterior 10,83; largura da cabeça 5,0; comprimento do olho 2,40; distância interorbital superior 2,54 e a inferior 3,33; comprimento mínimo da área malar 0,42; largura da mandíbula na base 1,0 .

Holótipo fêmea. Venezuela, Aragua: Rancho Grande, 9.VI.1967, R.L. Dressler leg. Depositado na Coleção Moure, DZUP.

Comentários. Lembra T. rubricata, que pode ser reconhecida pela área malar mais curta, cerca de um terço da largura da mandíbula na base e pelo colorido pálido da pilosidade dorsal do mesosoma (Fig.1). Na chave de URBAN (1967), sairia juntamente com $T$. dispar (Smith, 1854) pela área malar bastante larga. Thygater dispar tem os tergos pretos.

Etimologia. Dedicada ao Prof. Ubirajara R. Martins do Museu de Zoologia, Universidade de São Paulo.

\section{Thygater (Thygater) anae sp.n.}

Fig. 3

Diagnose. Fêmea com pilosidade amarelo-fulva no dorso do mesosoma, tegumento amarelo-acastanhado no metasoma e enegrecido no labro e clípeo, sem área lisa brilhante no meio do clípeo. Macho com franja bissinuada no quarto esterno e pilosidade plumosa nos trocânteres anteriores.

Holótipo fêmea. Tegumento preto na cabeça e mesosoma, com mancha subapical amarela nas mandíbulas, amarelo-acastanhado no lado ventral do terceiro flagelômero ao distal e nas tégulas; castanho-escuro nas pernas; amarelo-acastanhado nos tergos, com larga margem translúcida amarela do primeiro ao quarto tergo, o distal castanho-enegrecido; esternos castanho-pálidos com orla esbranquiçada.

Pilosidade amarelo-palha na cabeça, com área castanha no disco das paroculares inferiores, em parte das paroculares superiores e da fronte, e nas genas; amarelo-fulva no mesosoma, passando a esbranquiçada na face ventral dos mesepisternos; fracamente amarelada nos artículos basais das pernas, com poucos pêlos castanhos nos fêmures anteriores; nas tíbias e tarsos anteriores e medianos brancoacastanhada, tíbias e basitarsos posteriores amarelo-palha, os basitarsos com cerdas castanho-arruivadas na face ventral; amarelo-palha no tergo basal; amarelo-dourada

Revta bras. Zool. 16 (1): 213 - 220, 1999 
e curta do segundo ao quarto tergo, com cerdas castanhas longas e finas de permeio no quarto tergo; castanho-pálida no quinto e enegrecida no sexto tergo; esbranquiçada nos esternos, formando tufos laterais do terceiro ao quinto, castanho-fulva nos dois distais.
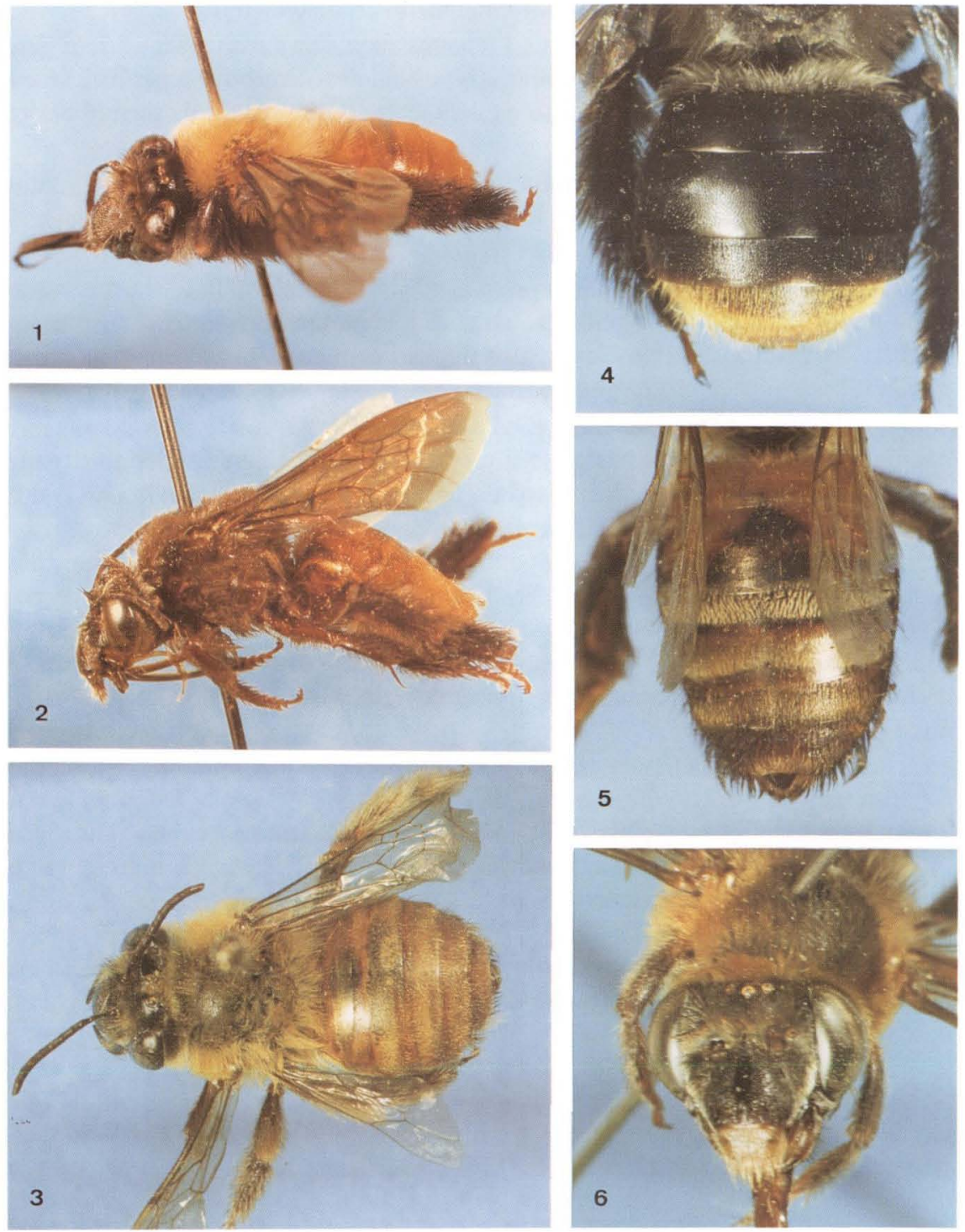

Figs 1-6. Fèmeas. (1) Thygater rubricata, (2) T. ubirajarai sp.n., holótipo de perfil; (3) T. anae sp.n., parátipo em vista dorsal; (4) T. minarum sp.n., ápice do mesosoma e tergos do holótipo; (5) T. laevis sp.n., ápice do mesosoma e tergos do holótipo; (6) T. armandoi sp.n., cabeça e parte do mesosoma do holótipo. 
Clípeo micro-reticulado, fracamente elevado no disco e sem formar carena mediana; disco posterior do mesoscuto com pontuação esparsa e micro-reticulação fraca; do segundo ao quarto tergo o tegumento brilhante; o segundo com pontuação rasa e esparsa, no terceiro e quarto com micro-reticulação e pontuação mais densa; margem larga sem pontos e com lineolado muito esparso no tergo basal.

Comprimento aproximado 12,17; comprimento da asa anterior 9,17; largura da cabeça 4,33; comprimento do olho 2,24; distância interorbital superior 2,36 e a inferior 2,68; comprimento mínimo da área malar 0,26; largura da mandíbula na base 0,69 .

Variação. Foi observada uma fêmea com pêlos castanho-claros nos cantos anteriores do mesoscuto, disco dos lobos pronotais e metade dorsal dos mesepisternos.

Alótipo macho. Tegumento preto com labro amarelo-pálido, antenas castanho-pálidas do segundo flagelômero ao apical, ventralmente; tégulas, tarsômeros medianos e distais castanho-claros; asas tingidas com acastanhado, margem translúcida esbranquiçada nos tergos e castanho-amarelada nos esternos.

Pilosidade branca na cabeça, com mescla de preta nos flancos do clípeo e nas paroculares inferiores passando a castanha nas paroculares superiores, parte superior da fronte e no vértice, disco do mesoscuto, escutelo, metade dorsal dos mesepisternos, metepisternos e flancos do propódeo; com pêlos castanho-escuros e brancos no metanoto; branca no restante do mesosoma e nos artículos basais das pernas; castanho-escura nas tíbias e basitarsos, nos demais tarsômeros castanho-pálida; branca na base do primeiro tergo, enegrecida e longa no disco e ápice; segundo e terceiro tergos com pêlos curtos enegrecidos, também na base do quarto; do ápice do quarto ao tergo distal amarelada com cerdas longas enegrecidas; amarelo-palha nos esternos.

Clípeo como na fêmea; trocanteres anteriores com pêlos plumosos quase tão longos como o fêmur do mesmo par; basitarsos posteriores com os lados sub-paralelos, aproximadamente cinco vezes tão longos como largos e não projetados distalmente; quarto esterno com franja apical completa, pouco densa, mais longa no meio e nos flancos; quinto esterno sem recortes, o sexto sem dobras ou tubérculos.

Comprimento aproximado 13,67 ; comprimento da asa anterior 9,83 ; largura da cabeça 3,87; comprimento do olho 1,96; distância interorbital superior 2,16 e a inferior 2,40; comprimento mínimo da área malar 0,30; largura da mandíbula na base 0,50 .

Holótipo fêmea. BrasiL, Espírito Santo: Santa Teresa, 8.XI.1967, C.T. \& C. Elias leg.. Alótipo, 5 parátipos fêmeas e 16 machos coletados com o holótipo. Da mesma localidade, os seguintes parátipos: C. \& C.T. Elias leg. 4.XII.66 uma fêmea; 25.X.67 cinco machos; 6-11.XI.67 duas fêmeas; 15.XI.67 quatro fêmeas e oito machos; 22.XI.67 quatro fêmeas e 14 machos; 30.XI.67 cinco fêmeas e dois machos; 26.I.68 uma fêmea. Rio de Janeiro: Rio de Janeiro, Alto da Tijuca, 16.I.51, Seabra leg. um macho; São Paulo: Barueri, XII.69, K. Lenko leg. um macho. Depositados na Coleção Moure, DZUP.

Comentários. Espécie parcialmente simpátrica com T. analis (Lepeletier, 1841) e T. palliventris (Friese, 1908). A fêmea de T. palliventris também tem o 
tegumento amarelo-acastanhado no metasoma; em $T$. analis os tergos são pretos com larga margem translúcida amarela; T. palliventris difere pelo labro amareloacastanhado, clípeo com margem amarelado-ocre e larga área lisa mediana desprovida de pontos, disco posterior do mesoscuto quase fosco e com pontuação densa.

No macho de $T$. analis a franja do quarto esterno é mais larga somente nos lados e os trocanteres anteriores têm pêlos longos cerdosos e justapostos, com pouquíssimas ramificações formando franja sedosa. Não é conhecido o macho de T. palliventris.

Na chave de URBAN (1967), o macho entraria em uma sub-divisão do dilema nove, com $T$. aethiops (Smith, 1854), espécie caracterizada pela área malar quase tão longa como a largura da base da mandíbula e o quarto esterno com o bordo obtuso-anguloso, com franja de comprimento uniforme; e a fêmea sairia ao lado de T. palliventris.

Etimologia. Em homenagem à Profa Ana Leuch Lozovei do Departamento de Patologia Básica, Universidade Federal do Paraná.

\section{Thygater (Thygater) minarum sp.n.}

Fig. 4

Diagnose. Fêmea com pilosidade enegrecida em grande parte do mesosoma e dos tergos, os pêlos muito curtos no segundo e terceiro tergos, não ultrapassando a margem; amarelo-dourada a amarelo-acastanhada nos tergos distais, tegumento amarelo-fulvo nos tergos distais.

Holótipo fêmea. Tegumento preto; amarelo-ferrugíneo no disco do labro, pequena mancha subapical amarela nas mandíbulas; asas enegrecidas e veias pretas; tarsômeros distais castanho-amarelados; faixa marginal do quarto tergo, todo o quinto e lados do sexto amarelo-fulvos; esternos castanhos com áreas amarelo-fulvas.

Pilosidade branca nas genas, lados do clípeo e das paroculares inferiores e em volta das antenas, preta no restante da cabeça; preto-acastanhada nos lobos pronotais, mesepisternos, quase todo o mesoscuto, escutelo, flancos do metanoto e do propódeo; com pêlos brancos em volta do mesoscuto, parte das áreas axilares, base das áreas dorso-laterais do metanoto, em volta dos lobos pronotais e na área subalar; com mescla de branca e enegrecida no disco do propódeo; preto-acastanhada nos artículos basais das pernas, preta nas tíbias e basitarsos, castanho-clara a amarelada nos tarsômeros distais. Branca na base do primeiro tergo, enegrecida e longa no disco, os pêlos mais curtos para os flancos deixando larga margem glabra; no segundo e terceiro preta, curta e esparsa, larga margem glabra no segundo, no terceiro os pêlos quase até o bordo; no quarto tergo amarelo-dourada com longas cerdas da mesma cor; no quinto tergo e flancos do sexto amarelo-acastanhada; castanho-clara nos dois esternos basais, nos demais esternos amarelo-fulva.

Clípeo com área deprimida brilhante mediana junto à sutura epistomal, com micro-reticulação fraca, sem carena discal mediana; palpos maxilares com o terceiro artículo mais longo que o segundo $(0,24 ; 0,30)$; tergos brilhantes com pontuação fina, o primeiro com margem larga sem pontos, no segundo e terceiro tergos a 
margem lisa estreita e uniforme, no segundo aproximadamente tão larga como o diâmetro do ocelo; mesoscuto com espaços grandes desprovidos de pontos na metade posterior do disco, igualando meio a um diâmetro de ocelo.

Comprimento aproximado 14,50; comprimento da asa anterior 10,0: largura da cabeça 4,67; comprimento do olho 2,40; distância interorbital superior 2,48 e a inferior 2,96; comprimento mínimo da área malar 0,28; largura da mandíbula na base 0,76 .

Holótipo fêmea. Brasil, Minas Gerais: Viçosa, 15.II.1987, G.A.R. Melo leg.. Depositado na Coleção Moure, DZUP.

Comentários. Na chave de URBAN (1967), sairia próxima de T. colombiana Urban, 1967, pelo tamanho reduzido dos pêlos do segundo e terceiro tergos e de $T$. micheneri Urban, 1967, pelo colorido. Em T. colombiana, os tergos têm pilosidade amarelo-dourada, muito curta, não atingindo o ápice no segundo e terceiro tergos. Além disso, estas espécies estão distanciadas geograficamente, $T$. colombiana foi coletada em Popayán, 6.800 pés, COLÔMBIA, no lado ocidental da cordilheira Central dos Andes. T. micheneri tem pilosidade muito curta no segundo tergo, no terceiro os pêlos ultrapassam o bordo; carena na metade apical do clípeo, pontuação densa no mesoscuto sem grandes espaços lisos entre os pontos; o terceiro artículo do palpo maxilar menor que o segundo e a área lisa da margem do segundo tergo mais larga no meio, quase tão larga como dois diâmetros de ocelo; é conhecida somente do México.

Etimologia. Nome alusivo ao estado de Minas Gerais.

\section{Thygater (Thygater) laevis sp.n.}

Fig. 5

Diagnose. Fêmea com pilosidade castanha no disco do mesoscuto e escutelo, amarelo-fulva em volta do mesoscuto; tergos amarelo-acastanhados com margem translúcida amarelada muito larga e quase desprovida de pontos.

Holótipo fêmea. Tegumento preto na cabeça e mesosoma, labro e orla apical do clípeo amarelo-acastanhados, desta cor também no lado ventral das antenas, do segundo flagelômero ao apical; tégulas translúcidas amareladas; asas tingidas com amarelo-méleo, $\mathbf{R}$ enegrecida, demais veias amarelo-acastanhadas; pernas castanhas. Tergo basal e áreas látero-basais do segundo amarelo-acastanhadas, restante do segundo tergo preto com manchas castanhas no disco e larga margem translúcida amarelo-pálida; terceiro e quarto tergos finamente pretos junto ao tomento basal, passando a castanhos e amarelo-acastanhados no disco, a margem translúcida amarelo-pálida muito larga, quinto e sexto tergos castanhos; esterno basal amareloacastanhado, do segundo ao quarto esterno castanho na base com margem translúcida amarelo-pálida, quinto e sexto castanhos.

Pilosidade amarelo-palha na cabeça; enegrecida no disco do clípeo, paroculares inferiores junto ao clípeo, metade dorsal da fronte, vértice e parte dorsal das genas junto às órbitas; castanha no mesoscuto, orlada com amarelo-fulva; castanha no escutelo; amarelo-palha no metanoto e propódeo; nos lobos pronotais e metade dorsal dos mesepisternos amarelo-fulva, branca na parte ventral dos mesepisternos 
e nos três artículos basais das pernas; castanha nas tíbias e enegrecida nos basitarsos, estes com as cerdas ventrais castanho-amareladas; amarelo-palha na base e nos flancos do primeiro tergo, castanha e longa no disco porém esparsa, mais curta para os lados; segundo tergo com pêlos castanhos curtos nos flancos e amarelados esparsos no disco; do terceiro ao quinto tergo com cerdas decumbentes castanhas, as cerdas esparsas no terceiro e mais numerosas nos seguintes, quarto tergo com pêlos amarelo-dourados nos cantos, no quinto castanho-clara e no sexto enegrecida; branca nos quatro esternos basais, curta no disco, formando franjas apicais e tufos nos lados do terceiro e quarto, no quinto esterno muito curta e esparsa, branca no disco e castanha para o ápice inclusive nos tufos laterais; no sexto esterno castanha.

Clípeo brilhante e micro-reticulado, com carena larga, baixa e sem pontos grandes na metade distal; quatro tergos basais com margem muito larga desprovida de pontos, o tegumento fracamente lineolado, com pontos esparsos somente nos flancos; pontuação fina e esparsa na metade posterior do disco do mesoscuto.

Comprimento aproximado 14,83 ; comprimento da asa anterior 9,0; largura da cabeça 4,67; comprimento do olho 2,32; distância interorbital superior 2,56 e a inferior 2,80; comprimento mínimo da área malar 0,26; largura da mandíbula na base 0,74 .

Holótipo fêmea. Venezuela, Bolivar: Santa Elena, 22.II.1967, R.L. Dressler leg.. Depositado na Coleção Moure, DZUP.

Comentários. Na chave de URBAN (1967) a fêmea entraria no ítem nove; distintinguindo-se pela larga margem lisa dos quatro tergos basais, carena larga e baixa no clípeo e a pilosidade castanha do disco do mesoscuto e escutelo.

Etimologia. Nome alusivo ao aspecto brilhante dos tergos.

\section{Thygater (Thygater) armandoi sp.n.}

Fig. 6

Diagnose. Fêmea com pilosidade castanha orlada com amarelo-fulva no mesoscuto e escutelo; tergos castanho-enegrecidos, labro amarelo-ocráceo; clípeo com carena baixa e depressão médio-basal brilhantes, como em $T$. palliventris; mesoscuto micro-reticulado com pontuação densa.

Holótipo fêmea. Tegumento preto, mancha subapical amarela nas mandíbulas; labro amarelo-ocráceo, antenas castanho-amareladas do terceiro flagelômero ao apical, ventralmente; tégulas castanho-amareladas; pernas com os mediotarsos e distitarsos amarelo-fulvos; nas anteriores predomina o castanho-enegrecido, com áreas castanho-amareladas na tíbia; nas medianas, coxa e trocanter castanho-escuros, fêmur com a face anterior castanho-amarelada, tíbia com grandes áreas enegrecidas e castanho-amareladas e basitarso enegrecido; nas pernas posteriores a coxa e o trocanter castanhos, demais artículos castanho-amareladas com áreas castanhas difusas, o basitarso com orla enegrecida dorsal; tergos castanho-enegrecidos, o basal com margem translúcida larga castanha e os dois seguintes com margem estreita amarelada; esternos castanho-amarelados com margem estreita esbranquiçada.

Pilosidade branca nos lados do clípeo e das paroculares inferiores, amarelo- 
palha na parte inferior da fronte e fulva com mescla de castanha no vértice e genas; enegrecida no disco das paroculares inferiores e parte dorsal da fronte; castanha no mesoscuto e escutelo com orla estreita amarelo-fulva, nos cantos anteriores do mesoscuto os pêlos com ápice castanho e amarelo-fulvos para a base; castanho-clara nas áreas dorso-laterais do metanoto; amarelo-palha na metade ventral dos mesepistenos e artículos basais das pernas, a metade dorsal dos mesepisternos amarelofulva; pernas anteriores e medianas com cerdas curtas decumbentes amarelas na face anterior do trocanter e base do fêmur, pêlos castanhos e amarelo-fulvos nas tíbias e basitarsos anteriores, as medianas com predominância dos amarelo-fulvos; também desta cor no bordo posterior das tíbias posteriores; nos basitarsos posteriores castanho-escura, com as cerdas ventrais castanho-arruivadas; amarelo-palha na base do primeiro tergo, castanho-pálida e alongada no disco e nos flancos, curta e enegrecida no restante até a borda; no segundo e terceiro tergos curtíssima, enegrecida e esparsa, não chegando à margem no meio do segundo porém nos lados e no terceiro ultrapassando um pouco a margem; no quarto tergo amarelo-fulva, com áreas laterais enegrecidas; preta nos dois tergos distais; branca e curta no disco dos esternos, formando franja longa do segundo ao quarto; no quinto e sexto esternos castanho-amarelada.

Clípeo micro-reticulado com carena larga e baixa, brilhante, nos dois terços apicais, brilhante também na depressão médio-basal; tergos com pontos finos densos, o basal com larga margem lisa e brilhante, um pouco lineolada, a margem lisa muito estreita nos seguintes.

Comprimento aproximado 13,0; comprimento da asa anterior 8,67; largura da cabeça 4,75; comprimento do olho 2,40; distância interorbital superior 2,56 e a inferior 2,68; comprimento mínimo da área malar 0,26; largura da mandíbula na base 0,80 .

Variação. Um parátipo de Sabará com mácula apical larga amarelo-ocre somente no meio do clípeo, nos lados o preto até a margem.

Holótipo fêmea. BrasiL, Minas Gerais: Viçosa, 22.XII.1985, L. Campos leg.. Parátipos - Minas Gerais: Sabará, 14.I.1996, F.A. Silveira leg. uma fềmea; Rio de Janeiro: Itatiaia, 20.VI.1941, J.F. Zikán leg. uma fêmea. Depositados na Coleção Moure, DZUP.

Comentários. Na chave de URBAN (1967) entraria em uma sub-divisão do dilema 10, ao lado de T. montezuma (Cresson, 1878), diferindo na pilosidade do mesoscuto.

Etimologia. Homenagem ao Prof. Armando Antunes de Almeida do Departamento de Zoologia, Universidade Federal do Paraná.

\section{REFERÊNCIA BIBLIOGRÁFICA}

URBAN, D. 1967 As espécies do gênero Thygater Holmberg, 1884. (Hymenoptera, Apoidea). Bol. Univ. Fed. Paraná, Zool., II (12): 177-309.

Recebido em 17.X.1997; aceito em 03.III.1999. 